\title{
RANCANG BANGUN POWER SUPPLY DC DENGAN TIGA KELUARAN BERBASIS MIKROKONTROLLER
}

\author{
Siti Saodah,Pajar Ramdani \\ Politeknik Negeri Bandung, Jurusan Teknik Konversi Energi \\ ss_herlina@yahoo.com
}

\begin{abstract}
Abstrak
Power supply DC merupakan suatu rangkaian elektronika yang mengubah arus listrik bolak balik (AC) menjadi arus listrik searah (DC) yang digunakan untuk mensuplai tegangan. Dalam pembuatan rangkaian power supply $D C$, dibutuhkan komponen elektronika yang terdiri transformator, rectifier, filetering dan IC sebagai regulator tegangan. Agar menghasilkan tegangan yang konstan, digunakan IC dengan series $78 X X$, dan untuk menghasilkan tegangan variable digunakan IC LM338. Mikrokontroller digunakan sebagai pengubah nilai analog keluaran power supply DC menjadi digital yang dapat ditampilkan di LCD. Untuk pembacaan arus, tegangan dan daya dibutuhkan sensor yang berfungsi sebagai pendeteksi sinyal yang dapat ditampilkan di LCD, sensor yang digunakan pada power supply DC yaitu sensor arus ACS712, dan sensor tegangan dengan metode pembagi tegangan. Dari hasil pengujian, power supply DC dapat menghasilkan tegangan konstan tanpa beban sebesar $4,96 \mathrm{~V}$ dan $12 \mathrm{~V}$ dan tegangan variable 1,25-22,88V pada saat kondisi beban nol, sedangkan pada saat semua keluaran berbeban power supply DC mengalami drop tegangan sebesar 9,54V untuk keluaran konstan $12 \mathrm{~V}$ dan $17,32 \mathrm{~V}$ untuk keluaran variable. Efisiensi yang didapat dari power supply DC yang dibuat adalah sebesar $73.86 \%$.
\end{abstract}

Kata kunci : power supply DC, mikrokontroller, sensor, LCD.

\begin{abstract}
$D C$ power supply is an electronic circuit that converts electrical current into alternating current unidirectional electric used to supply voltage. In making the DC power supply circuit, electronic component consisting needed transformers, rectifiers, filetering and IC as a voltage regulator. To produce a constant voltage then used the IC with the 78XX series, and used to generate variable voltage IC LM338. Components needed for the sake of readability users $D C$ power supply is used microcontroller that functions as a modifier value of analog output into digital DC power supply that can be displayed on the LCD. For reading the current, voltage and power required detection sensor that functions as a signal that can be displayed on the LCD, sensor used on the DC power supply ACS712 current sensor, and the sensor voltage with a voltage divider method. From the test results can generate $D C$ power supply constant voltage without a load of $4,96 \mathrm{~V}$ and $12 \mathrm{~V}$ and variable voltage $1,25-22,88 \mathrm{~V}$ during zero load condition, whereas when all output load DC power supply having a voltage drop of $9.54 \mathrm{~V}$ for constant $12 \mathrm{~V}$ and output to output variable $17,32 \mathrm{~V}$. Efficiencies gained from the DC power supply is made at $73.86 \%$.
\end{abstract}

Keywords: DC power supply, microcontroller, sensors, $L C D$.

\section{PENDAHULUAN}

Power supply DC merupakan suatu rangkaian elektronika yang mengubah arus listrik bolak balik menjadi arus litrik searah yang digunakan untuk mensuplai tegangan, misalnya mensuplai tegangan ke hardisk, fan, dan lain lain. Power supply DC menjadi bagian yang penting dalam elektronika yang berfungsi sebagai pemasok energi listrik untuk kebutuhan alat elektronika. Secara umum prinsip rangkaian power supply DC terdiri atas komponen utama yaitu: transformer, dioda dan kondensator. Dalam pembuatan rangkaian power supply DC, selain menggunakan komponen utama juga diperlukan komponen pendukung agar rangkaian tersebut dapat berfungsi dengan baik. Komponen pendukung tersebut antara lain : sakelar, sekering (fuse), lampu indicator, , printed circuit board (PCB), kabel serta chasis. Penelitian ini mencoba membuat hardware power supply DC dengan 3 keluaran, 1 keluaran yang dapat diubah-ubah dan 2 keluaran tetap dengan menampilkan arus, tegangan, dan daya yang 
dapat ditampilkan di LCD. Untuk mendapatkan 3 keluaran pada power supply dibutuhkan komponen elektronika yang dinamakan regulator tegangan IC (integrated circuit) merupakan komponen elektronika yang berfungsi sebagai pengatur tegangan dc dan

\section{METODOLOGI}

Peneleitian ini mencoba dengan mengembangkan tampilan keluaran power supply DC yang dapat ditampilkan secara digital menggunakan mikrokontroller dan LCD sebagai tampilan. Pada rangkaian power supply DC digunakan regulator tegangan LM 7805 dan LM 7812 untuk keluaran tetap dan LM 338 untuk keluaran variable.

Regulator tegangan dengan menggunakan komponen utama integrated circuit (IC) mempunyai keuntungan lebih praktis dan umunya menghasilkan umumnya menghasilkan penyetabilan tegangan yang lebih baik (surjono, 2009). Ada beberapa integrated ciruit (IC) yang menghasilkan tegangan positif maupun tegangan negatif dan ada pula yang menghasilkan tegangan yang bisa diatur. Integrated circuit (IC) tipe LM78XX menghasilkan tegangan positif dan integrated circuit (IC) tipe LM 79XX menghasilkan tegangan negatif. Untuk regulasi tegangan dapat menggunakan persamaan 1

Vout $=\operatorname{Vref}\left(1+\frac{R 2}{R 1}\right)+\operatorname{Iadj} \cdot R 2$

dengan,

Vout $=$ Tegangan keluaran (V)

Vref = Tegangan refrensi IC yang digunakan (V)

$\mathrm{R} 2$ = resistor 2

$\mathrm{R} 1=$ resistor 1

Iadj. $=$ Typikal arus IC .

Hasil keluaran power supply DC kemudian dipasang sensor tegangan dan sensor arus ACS712 yang dihubungkan dengan mikrokontroller untuk pengkonversian nilai analog ke digital. Untuk sensor tegangan digunakan metode pembagi tegangan dengan memasang 2 buah resistor sebelum dihubungkan dengan mikrokontroller, adapun persamaan yang digunakan untuk metode pembagi tegangan adalah sebagai berikut. menstabilkan tegangan. Selain itu untuk menampilkan keluaran yang dihasilkan oleh power supply DC di LCD dibutuhkan sensor tegangan, arus dan daya untuk pembacaan mikrokontroller yang berfungsi sebagai tampilan display di LCD.

$\mathrm{Vo}=\mathrm{VI} \cdot \frac{R 2}{R 1+R 2}$

Sensor arus yang digunakan adalah Sensor $e f e k$ hall dapat digunakan untuk menyensor arus karena sensor efek hall merespon medan magnet, sedangkan medan magnet yang ditimbulkan arus selalu sebanding dengan besar arusnya. Ini membuat sensor efek hall baik digunakan sebagai sensor arus. Sensor arus ACnya adalah sensor efek hall yang dapat mengukur medan magnet disekitar kawat berarus. Agar medan magnetnya cukup kuat dan bisa terukur sensor efek hall, maka dibuat lilitan dengan inti ferit yang medan magnetnya dibuat menembus sensor. Arus yang dilewatkan ke lilitan adalah arus yang telah disearahan terlebih dahulu. Jumlah lilitan dan inti ferit sangat mempengaruhi besar penguatan medannya. Syarat dari sensor efek hall menunjukkan medan nol pada tegangan 2,5 V. Tegangannya akan berubah jika terjadi perubahan medan magnet. Syarat ini diperkuat, dan kemudian difilter sehingga outputnya berupa tegangan DC yang berbanding lurus terhadap perubahan arusnya. Sensor arus dengan prinsip efek hall dapat mengukur arus dengan sangat tepat. Di samping itu sensor medan magnet ini dapat dimanfaatkan dalam banyak keperluan, karena medan magnet dapat direspon dalam range frekuensi yang cukup besar. Semuanya tergantung dari kualitas penguatan sinyalnya.

Hall effect sensor yang diaplikasikan untuk mengukur arus listrik. Ampere meter saat ini penggunaannya dipasang secara seri dengan memutuskan kabel yang ada pada rangkaian atau menggunakan tang Ampere. Oleh karena itu dilakukan penelitian untuk mengukur arus listrik menggunakan hall effect sensor dengan metode mendeteksi besarnya medan magnet pada suatu kabel yang dialiri arus listrik. Jadi untuk mengukur arus, hall effect sensor hanya didekatkan pada kabel yang akan diukur. 
Dalam pembuatan ampere meter ini menggunakan sebuah mikrokontroler tipe AVR ATMega 8. AVR ATMega 8 memiliki fitur tambahan seperti ADC internal dan internal clock osscilator. Pada alat ukur arus ini AVR berfungsi sebagai pengatur dari komponen seperti LCD (Liquid Crystal Display) dan sebagai pengolah data. Output dari sensor diolah terlebih dahulu oleh rangkaian amplifier baru kemudian data analog yang ada diubah oleh AVR menjadi data digital dan ditampilkan hasilnya melalui LCD.

Skema pembuatan alat yang dibuat adalah sebagai berikut.

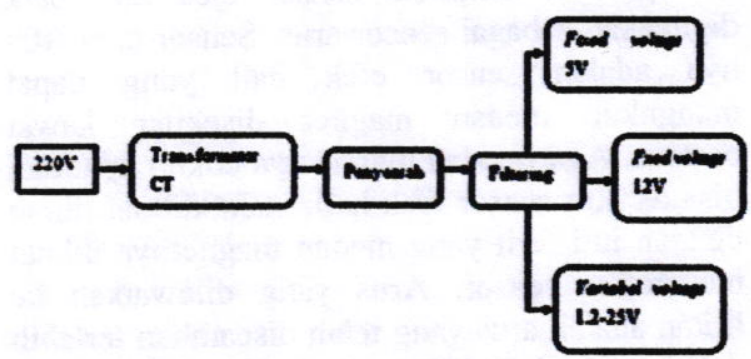

Gambar 1. Skema pembuatan power supply DC

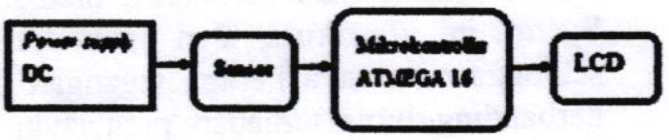

Gambar 2 Konfigurasi power supply DC dengan mikrokontroller

Untuk mengaktifkan mikrokontroller agar dapat mengolah data nilai analog dari sensor yang dikonversi menjadi nilai digital digunakan VCC sebesar $5 \mathrm{~V}$.

Untuk mengetahui apakah pembuatan hardware power supply DC dengan tiga keluaran berbasis mikrokontroller AVR sesuai dengan yang diharapkan, maka diperlukan langkah langkah pengujian untuk mengetahui:

1. Mengetahui fungsi alat power supply DC, dapat menghasilkan tegangan keluaran dengan 2 keluaran konstan sebesar $5 \mathrm{~V}$ dan $12 \mathrm{~V}$, dan keluaran variable $1.2-25 \mathrm{~V}$
2. Power supply DC dapat ditampilkan di LCD dengan menggunakan mikrokontroller AVR

3. Mengetahui karakteristik alat, dilihat dari gelombang tegangan, dan pembebaban pada tegangan keluaran power supply DC

Tahapan pengujian alat terdiri dari

1. Tentukan titik titik pengujian

2. Mempersiapkan peralatan dan alat ukur yang akan digunakan

3. Pengecekan peralatan dan alat ukur yang akan digunakan

4. Memastikan rangkaian alat tersambung dengan benar

5. Pengambilan data yang dibutuhkan

6. Menganalisa data yang telah didapatkan.

\section{HASIL DAN PEMBAHASAN}

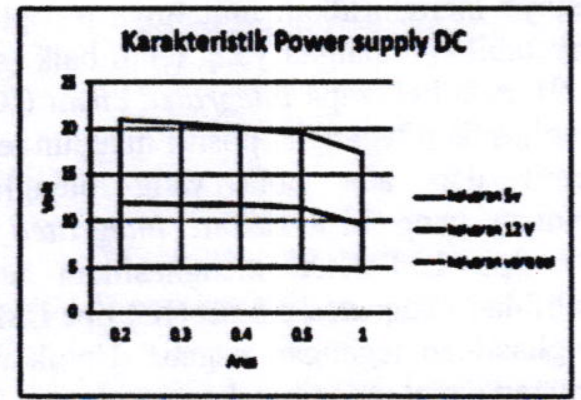

Gambar 3 Karakteristik power supply DC

Gambar 3 menunjukan karakteristik power supply DC yang menggambarkan hubungan arus terhadap tegangan pada saat semua keluaran dibebani. Untuk melihat karakteristik dari power supply DC yang telah dibuat maka dilakukan pengukuran atau pengujian sebanyak 5 data dengan arus yang sama pada setiap keluaran. Dari gambar 3 dapat dilihat bahwa tegangan semakin turun pada saat semua keluaran digunakan, keluaran yang menghasilkan drop tegangan paling besar adalah keluaran $12 \mathrm{~V}$ dengan arus $1 \mathrm{~A}$ menghasilkan tegangan keluaran sebesar 9.54 dan tegangan keluaran variable dengan tegangan keluaran 17.32V. Semakin menurunnya tegangan keluaran power supply DC pada saat semuanya terbebani disebabkan oleh beberapa faktor diantaranya tegangan input kecil, arus beban naik, kemampuan line regulation dan load 
regulation dari regulator tegangan yang digunakan tidak baik.

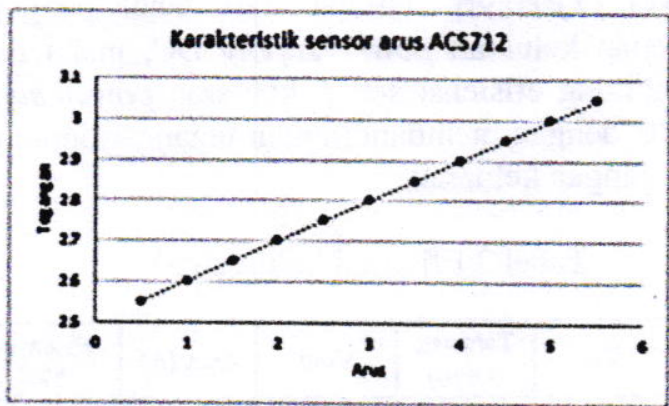

Gambar 4 Karakteristik sensor arus ACS712

Dari gambar 4, menunjukkan karakteristik sensor arus ACS712 yang digunakan pada power supply DC. Dari gambar tersebut dapat dilihat bahwa arus naik maka tegangan naik, sensor arus ACS712 dikalibrasi dari pabrik yang membuat, pada saat tidak ada arus yang mengalir tegangan pada sensor arus sebesar $2.5 \mathrm{~V}$ dengan Vcc sebesar 5V. Dilihat dari gambar IV.16 menunjukan bahwan kenaikan tegangan bersifat linear dengan kenaikan tegangan sebesar $0.1 \mathrm{~V}$ dengan kenaikan arus sebesar 1A.

Keluaran dari power supply DC kemudian dihubungkan dengan mikrokontroller, pada port A. Pada port A, data yang masuk kemudian diolah menjadi nilai digital.Bit yang digunakan pada mikrokontroller untuk pengolahan nilai analog menjadi nilai digital adalah 10 bit yang artinya maksimal data digitalnya $2^{10}-1=1023$. Pengurangan 1 dimaksudkan karena data diawali dari nilai 0-1023 yang berjumlah 1024 .

Nilai tegangan yang masuk ke port A sebesar $5 \mathrm{~V}$ dengan tegangan referensi sebesar $5 \mathrm{~V}$, dari nilai tegangan referensi, nilai input ke port $\mathrm{A}$, dan bit yang digunakan maka digunakan persamaan berikut.

$$
\begin{array}{r}
\mathrm{ADC}=\frac{\text { Vin bit yang dipakai }}{\text { Vref }} \\
\mathrm{ADC}=\frac{5 \times 1023}{5} \\
\mathrm{ADC}=1023
\end{array}
$$

Dari nilai $\mathrm{ADC}$ tersebut dapat diasumsikan bahwa nilai tegangan sebesar $5 \mathrm{~V}$ sama dengan nilai ADC sebesar 1023. Dengan asumsi tersebut, maka dapat dihitung nilai digital untuk keluaran power supply DC.

Dari hasil pengujian didapat untuk keluaran konstan $5 \mathrm{~V}$ tegangan yang didapat adalah 4.96 sedangkan untuk keluaran konstan $12 \mathrm{~V}$ adalah sebesar 12,04V. Dari hasil pengujian tersebut maka didapat nilai $\mathrm{ADC}$ untuk tampilan display dengan menggunakan persamaan

$>$ Keluaran 5V

Untuk menampilkan nilai $4,96 \mathrm{~V}$ pada LCD maka digunakan persamaan sebai berikut.

$$
\begin{gathered}
\text { Nilai }=\frac{\text { Bit yang digunakan }}{A D C} \\
4,96 \mathrm{~V}=\frac{1023}{A D C} \\
\mathrm{ADC}=\frac{1023}{4,96} \\
\mathrm{ADC}=206.25
\end{gathered}
$$

Keluaran 12V

Untuk menampilkan nilai $12 \mathrm{~V}$ pada $\mathrm{LCD}$ maka digunakan persamaan sebagai berikut.

$$
\begin{gathered}
\text { Nilai }=\frac{\text { Bit yang digunakan }}{A D C} \\
12 \mathrm{~V}=\frac{1023}{A D C} \\
\mathrm{ADC}=\frac{1023}{4,96} \\
\mathrm{ADC}=85,25
\end{gathered}
$$

Dari hasil pengujian, tegangan maksimum yang dihasilkan oleh power supply DC sebesar 22.88, maka digunakan persamaan berikut.

$$
\begin{aligned}
\text { Nilai }=\frac{\text { Bit yang digunakan }}{A D C} \\
22.88 \mathrm{~V}=\frac{1023}{A D C} \\
A D C=\frac{1023}{22.88} \\
A D C=44,71
\end{aligned}
$$

Dari perhitungan nilai konversi analog ke digital diatas kemudian dilakukan pembuatan program pada mikrokontroller.Untuk konversi nilai analog atau pembacaan sensor arus pada display menggunakan mikrokontroller, dililihat dari karakteristik sensor dan data sheet bahwa sensor arus ACS712 memiliki output yang linear sebesar $100 \mathrm{mV} / \mathrm{A}$. Yang artinya pada setiap kenaikan 1A maka tegangan akan naik sebsar $100 \mathrm{mV}$, dengan setpoint pada saat tidak ada arus tegangan outputnya 2,5V. Jika dibuatkan kesetaraan antara arus dan tegangan dapat dilihat pada tabel 1 sebagai contoh untk nilai konversi ADC. 
Tabel 1 Kesetaaraan antara arus dan tegangan

\begin{tabular}{|c|c|c|}
\hline $\begin{array}{c}\text { Tegangan } \\
\text { sensor (Volt) }\end{array}$ & $\begin{array}{c}\text { Keterangan } \\
\text { (Arus) }\end{array}$ & ADC \\
\hline 2.5 & 0 & 511.5 \\
\hline 2.6 & 1 & 531.9 \\
\hline 2.7 & 2 & 552.4 \\
\hline 2.8 & 3 & 572.8 \\
\hline 2.9 & 4 & 593.3 \\
\hline 3.0 & 5 & 613.8 \\
\hline
\end{tabular}

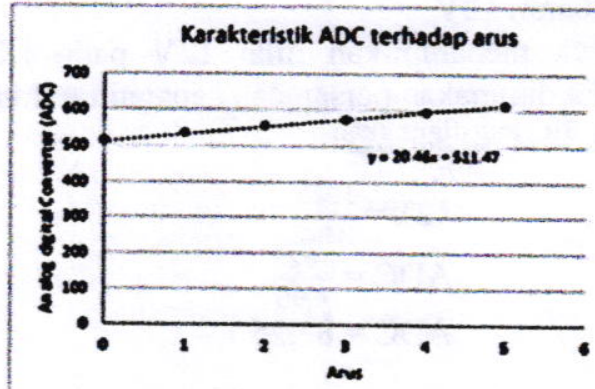

Gambar 5 ADC terhadap arus

Pada gambar 5 menunjukkan karakteristik ADC terhadap arus, dari gambar tersebut dapat dilihat bahwa hubungan ADC terhadap arus linier, dimana pada saat arus naik maka nilai $\mathrm{ADC}$ nyapun akan semakin besar.

Dari hubungan karakteristik ADC terhadap arus, didapat persamaan linier $\mathrm{y}=20.46 \mathrm{x}$ +511.47, persamaan linier tersebut digunakan persamaan untuk menentukan nilai arus yang akan ditampilkan di LCD. Adapun persamaan yang digunakan untuk menentukan nilai arus pada LCD adalah sebagai berikut.

Diketahui : $\mathbf{x}=$ nilai arus

$$
\mathrm{y}=\text { nilai } \mathrm{ADC}
$$

$\mathrm{y}=20.46 \mathrm{x}+511.47$

$\mathrm{x}=(\mathrm{y}-511.47) / 20.46$

nilai arus $=($ nilai $\mathrm{ADC}-511.47) / 20.46$
Persamaan yang didapat dari persamaan linier untuk menampilkan arus pada LCD adalah nilai arus $=$ (nilai ADC511.47)/20.46. Dilihat dari tabel pengujian setiap keluaran power supply DC, maka dapat dihitung efisiensi setiap keluaran power supply DC dengan membandingkan tegangan input dan tegangan keluaran.

Tabel 2 Efisiensi keluaran 5V

\begin{tabular}{|c|c|c|c|c|}
\hline Vin & $\begin{array}{c}\text { Tahanan } \\
\text { (Ohm) }\end{array}$ & Vout & Arus (A) & $\begin{array}{c}\text { efisensi } \\
\%\end{array}$ \\
\hline 10.08 & 24.2 & 4.96 & 0.1 & 49.20635 \\
\hline 9.73 & 20.08 & 4.96 & 0.2 & 50.97636 \\
\hline 9.45 & 15.7 & 4.96 & 0.3 & 52.48677 \\
\hline 9.38 & 14 & 4.96 & 0.4 & 52.87846 \\
\hline 9.18 & 11.9 & 4.96 & 0.5 & 54.0305 \\
\hline 9.04 & 10.4 & 4.96 & 0.6 & 54.86726 \\
\hline 8.98 & 9.7 & 4.96 & 0.7 & 55.23385 \\
\hline 8.78 & 8.5 & 4.96 & 0.8 & 56.49203 \\
\hline 8.54 & 8 & 4.96 & 0.9 & 58.07963 \\
\hline 8.36 & 5.5 & 4.96 & 1 & 59.33014 \\
\hline 8.05 & 4.8 & 4.21 & 1.1 & 52.29814 \\
\hline \multicolumn{5}{|c}{ rata rata } \\
\hline
\end{tabular}

Tabel 3 Efisiensi keluaran 12V

\begin{tabular}{|c|c|c|c|c|}
\hline Vin & $\begin{array}{c}\text { Tahanan } \\
\text { (Olum) }\end{array}$ & Vout & Arus (A) & $\begin{array}{c}\text { efisiensi } \\
\%\end{array}$ \\
\hline 16.97 & 69.7 & 12 & 0.1 & 70.71302 \\
\hline 15.78 & 55.5 & 12 & 0.2 & 76.04563 \\
\hline 15.35 & 39.9 & 12 & 0.3 & 78.1759 \\
\hline 15.28 & 33.8 & 12 & 0.4 & 78.53403 \\
\hline 15.15 & 30 & 12 & 0.5 & 79.20792 \\
\hline 15.12 & 27.1 & 12 & 0.6 & 79.36508 \\
\hline 14.96 & 24.6 & 12 & 0.7 & 80.2139 \\
\hline 14.78 & 22.2 & 12 & 0.8 & 81.1908 \\
\hline 14.64 & 20.6 & 12 & 0.9 & 81.96721 \\
\hline 14.38 & 19.1 & 12 & 1 & 83.44924 \\
\hline 14.08 & 17.9 & 11.67 & 1.1 & 82.88352 \\
\hline \multicolumn{4}{|c|}{ rata } & 79.24966 \\
\hline
\end{tabular}


Tabel 4 Efisiensi keluaran variabel

\begin{tabular}{|c|c|c|c|c|}
\hline Vin & $\begin{array}{c}\text { Tahanan } \\
\text { (Olmi) }\end{array}$ & Vout & Arus (A) & $\begin{array}{c}\text { Efisiensi } \\
\%\end{array}$ \\
\hline 23.8 & 29.2 & 20.35 & 0.5 & 85.5042 \\
\hline 22.2 & 19.7 & 19.33 & 1 & 87.07207 \\
\hline 21.7 & 13 & 18.5 & 1.5 & 85.25346 \\
\hline 20.4 & 11.3 & 17.95 & 2 & 87.9902 \\
\hline 19.8 & 10.5 & 17.48 & 2.5 & 88.28283 \\
\hline 19.4 & 9.8 & 17.07 & 3 & 87.98969 \\
\hline 18.6 & 8.2 & 16.66 & 3.5 & 89.56989 \\
\hline 17.9 & 7.4 & 16.14 & 4 & 90.1676 \\
\hline 17.6 & 6.6 & 15.94 & 4.5 & 90.56818 \\
\hline 17.3 & 5.1 & 15.55 & 5 & 89.88439 \\
\hline 17.01 & 4.3 & 15.12 & 5.5 & 88.88889 \\
\hline \multicolumn{4}{|c|}{ rata rata } & 88.28831 \\
\hline
\end{tabular}

Dilihat dari tabel diatas, maka untuk efisiensi power supply DC dapat didapatkan dari setiap rata rata efisiensi setiap keluaran power supply DC. Maka untuk efisiensi power supply DC adalah sebagai berikut.

$\eta=\frac{e f f 5 V+e f f 12 V+e f f \text { variabel }}{3}$

$\eta=\frac{54,17+79.24+88.28}{3}$

Maka efisiensi yang dihasilkan untuk power supply DC dengan menggunakan regulasi tegangan adalah sebesar $73.86 \%$.

\section{KESIMPULAN}

Dari proses pembuatan dan analisis dapat disimpulkan:

1. Keluaran power supply DC yang dihasilkan tanpa beban adalah $4.96 \mathrm{~V}$ dan $12 \mathrm{~V}$ untuk tegangan konstan dan $1.25-22.88 \mathrm{~V}$ untuk tegangan variable. Setiap tegangan keluaran power supply DC mengalami penurunan tegangan pada saat adanya perubahan beban, untuk tegangan konstan $5 \mathrm{~V}$ dan $12 \mathrm{~V}$ mengalami penurunan tegangan pada saat arus sebesar 1.1A dan tegangan keluaran variable mengalami penurunan tegangan setiap perubahan arus yang disebabkan karena menurunnya tegangan input pada regulator tegangan LM338

2. Efisiensi power supply DC yang dihasilkan dalam meregulasikan tegangan sebesar $73.86 \%$

\section{Saran}

Dari hasil pengujian keluaran power supply DC pada saat berbeban adanya drop tegangan, agar tidak terjadi drop tegangan disarankan pada power supply DC ditambahkan komponen yang berfungsi sebagai penguat arus dan tegangan yaitu transistor dan op-amp.l

\section{DAFTAR PUSTAKA}

1. anam, m. c. (2008). modul elektronika. pasuruan: smp negeri 1 pasuruan.

2. Rasid, M. H. (1999). elektronika daya. jakarta: PT Prenhallindo.

3. surjono, h. d. (2009). elektronika lanjut. jember: dhega febiharsa.

4. Data Sheet LM 78XX, Texas Instrument Inc, 2005

5. Data Sheet LM 338, Texas Instrument Inc, 2005

6. Data Sheet ACS712, Allegro, 2 